\title{
in vitro Cytotoxicity examination of the seashell and fish scale substances embedded with high degree of compactness in polyethylene composite
}

DOI:10.36909/jer.ICMMM.12431

\author{
A Anandha Moorthy ${ }^{1}$, Natarajan Nanjappan ${ }^{2}$, C. Balaji Ayyanar ${ }^{3}$, D. Dinesh ${ }^{1}$ \\ ${ }^{1}$ Department of Mechanical Engineering, Bannari Amman Institute of Technology, \\ Sathyamangalam - 638401 \\ ${ }^{2}$ Department of Mechanical Engineering, Excel Engineering College, Namakkal - 637303, \\ Tamilnadu, India \\ ${ }^{3}$ Department of Mechanical Engineering, Coimbatore Institute of Technology, Coimbatore - \\ 641 014, Tamilnadu, India. \\ *Email: anandhamoorthya @ bitsathy.ac.in; Corresponding Author.
}

\begin{abstract}
The organic response of polymer composites is facilitated by adding natural filler materials. Several new composite formulations claim to reduce the environmental impact. The present study assessed the cytotoxic responses of seashell and fish scale filled composite materials. The Polyethylene high-density (PEHD), 30 wt. \% of the seashell and 30 wt. \% of a seashell and fish scale combinations blended with the polymer matrix composites with 10:3 proportion (PEHD $100 \mathrm{~g}$ :Reinforcements $30 \mathrm{~g}$ ), and are then fabricated by the plastic injection molding machine. To better imitator the microstructure and the mineral component of natural bone, novel hydroxyapatite / polymer composite scaffolds are allowed to interact 10, 20, 30, 40 and $50 \mu \mathrm{l}$ of standard fresh cell culture medium for 24 hours. Morphology of cell, cell viability, and the effect of Cytotoxicity on polyethylene based composite samples were examined through ISO 10993:5, and 10993:12 test standards. The percentage of cell viability and the level of toxicity were compared.
\end{abstract}

Key words: seashell; fish scale; particulates; filler; PEHD; matrix; in vitro Cytotoxicity; MG63 cells. 


\section{INTRODUCTION}

The hydroxyapatite was extracted from seashell and utilized for biomedical application. It's an inexpensive and earth-friendly microwave radioactivity technique to make nHAp extract from (Anadara Granosa) seashell (Dhanaraj \& Suresh, 2018) also wet chemical reaction route was used to synthesize the nano hydroxyapatite from the powdered form of the seashells (Morteza Asadollahzadeh et al., 2019).

Quite a lot of past years biologically derived natural materials such as fish bone shell (Morteza Asadollahzadeh e al., 2019) bovine bone (Hassan Nosratiac et al., 2021 \& ClavijoMejíaab et al., 2020) and egg shells (Kristine Salma-Ancane \& Liga Stipniece Zilgma Irbe, 2016), coral (Fatemeh Heidari et al., 2020 \& Francesca Cestari et al., 2021) have been converted into useful biomaterials like hydroxyapatite nanoparticles. Nano hydroxyapatite has superior bioactivity than coarser crystals and its morphology and dimensions of hydroxyapatite nanocrystals have an important role in biomedical applications (Muhamamd Auchar Zardari, 2020 \& Payam Majedi et al., 2019).

The enhanced properties such as material strength, hardness and young's modulus are achieved by tailor made polymer matrix composite reinforced with natural fibers with Polyethylene high-density (PEHD). In addition to that, desired biological properties of biocompatibility and no toxicity also achieved (Fereydoun Pourdanesh et al., 2014). The cell morphology, cell viability, and direct Cytotoxicity level of particulate reinforced composite samples were experimented as per ISO 10993:5 and ISO 10993:12 testing methods. After 24 h of contact, MG-63 cell with 30 wt. \% fish scale reinforced PEHD based composite exhibited none to the Cytotoxicity reactivity. Cytotoxicity level of the fish scale particulates embedded polymer matrix composite exhibits low toxic level (Balaji Ayyanar \& Marimuthu, 2019) as compared with standard value. Recent trends on application and manufacturing process of HAp nanoparticles are discussed. The chemistry and applications of HAp are accurately matched with natural minerals (Baolin Huang et al., 2015).

The main intention of this experimentation is to develop polymer composites with naturally accessible Hydroxyapatite from seashell (Laevistrombus canarium) and fish scale of Catla (Labeo Catla), like as human teeth and bone chemical composition. It was utilized as reinforcement particulates in polyethylene thermoplastic to achieve biocompatibility and excellent thermo mechanical properties. Subsequently, both are having mineral and the matrix 
structure like as human bone and teeth. With reference to the literature review, a new combination of (i) seashell particulates (ii) combinations of fish scale and seashell particulates embedded polymer matrix composite has been manufactured using plastic injection molding method (Anandha Moorthy Appusamy et al., 2018) and the Cytotoxicity study has been experimented.

In order to perform the in vitro Cytotoxicity experimentation, five dissimilar mixers with $(10,20,30,40 \& 50 \mu \mathrm{l})$ concentration of liquid extracted from (i) 30 wt. \% seashell particulates (ii) 30 wt. \% of seashell and the fish scale mixture reinforced polymer matrix composite material permitted to chemically react with MG63 cells for 24 hours. The present examinations, cell morphology of bio reinforcement particulates embedded polymer matrix composite samples were experimented and the research outcomes were compared with standard fresh cell culture medium. The levels of non-Cytotoxicity (low to mild level) results are essential to adopt the developed specimen in the place of biomaterials. The developed PEHD based polymer matrix composite specimen exhibits zero level of Cytotoxicity in the MG 63 cell line.

\section{MATERIALS}

The matrix material, PEHD (High Density Poly Ethylene) is procured from Varsha Polymers (India). Tensile strength of the matrix material is $16 \mathrm{MPa}$ and other thermo-physical properties are listed in Table 1.

Table 1. Thermo-Physical Properties of Polyethylene high-density

\begin{tabular}{|c|l|l|}
\hline S. No & \multicolumn{1}{|c|}{ Material Property } & \multicolumn{1}{c|}{ Values } \\
\hline 1 & Melting temperature & $125^{\circ} \mathrm{C}$. \\
\hline 2 & Material density & $0.940 \mathrm{~g} / \mathrm{cm}^{3}$ \\
\hline 3 & Thermal conductivity & $0.44 \mathrm{~W} / \mathrm{m} .{ }^{\circ} \mathrm{C}$ \\
\hline 4 & Latent heat for fusion & $178.6 \mathrm{~kJ} / \mathrm{kg}$. \\
\hline 5 & Specific heat capacity & $1330-2400 \mathrm{~J} / \mathrm{kg}-\mathrm{K}$ \\
\hline 6 & Crystallization Temperature & $111^{\circ} \mathrm{C}$. \\
\hline
\end{tabular}

White color seashell (Laevistrombus Canarium) and the scale particulates of Catla fish (Labeo Catla) were used as reinforcement in polymer composite. The density of a seashell and fish scale is $1.2 \& 0.9 \mathrm{~g} / \mathrm{cm}^{3}$. From National Centre for Cell Science (NCCS), Pune, India, the required MG-63 cell line derived from an osteosarcoma has been procured and the required 
cell culture has processed in biotechnology research laboratory to perform in-vitro experimentation.

\section{METHODOLOGY}

The general processing method was followed to develop the natural particulates reinforced polymer composite material. Figure 1 shows the procedure and process carried out to make required composite specimen.

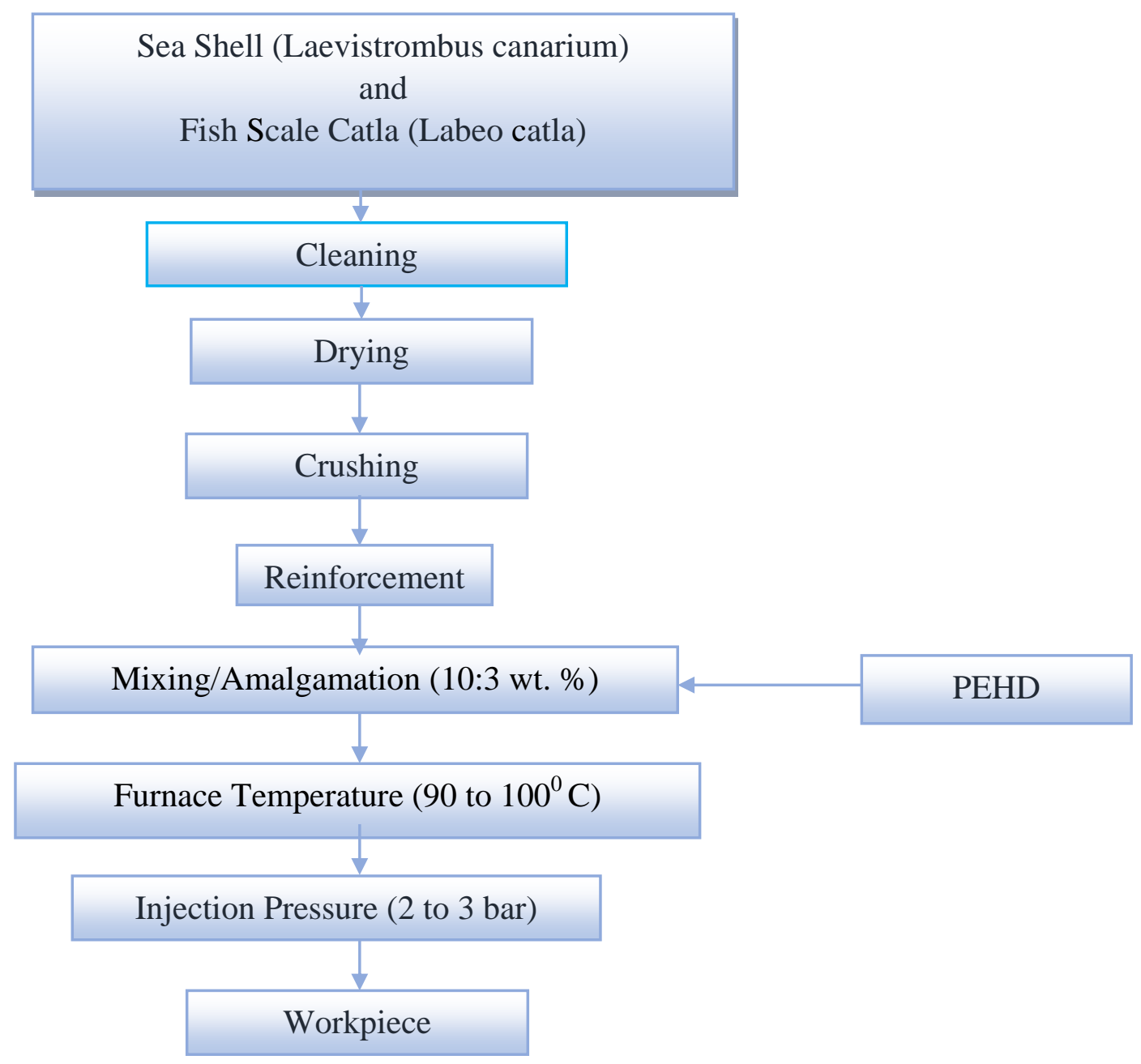

Figure 1. Methodology

In order to produce the required composite specimens, (i) $30 \mathrm{wt} \%$ of white seashell + PEHD and (ii) 30 wt. \% of a white seashell and Catla - fish scale mixture embedded with PEHD composites in 10:3 (Polyethylene $100 \mathrm{~g}$ : Reinforcements $30 \mathrm{~g}$ ) ratio. PEHD granules and filler materials were preheated at $60^{\circ} \mathrm{C}$ about 60 minutes and then introduced into the heating chamber of molding machine for additional heating as shown in Figure 2. 


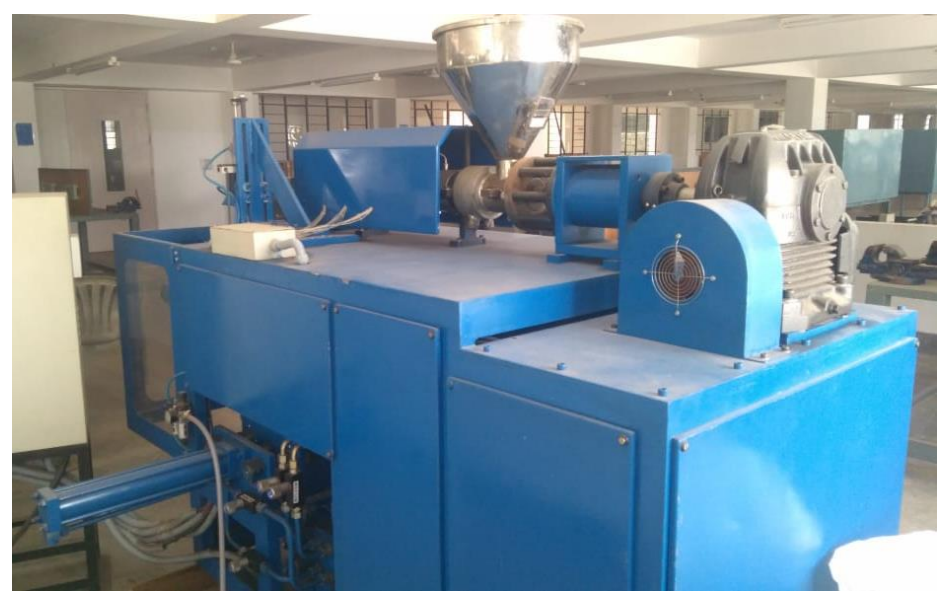

Figure 2. Plastic Injection Molding Machine

The temperature has been maintained from 90 to $100^{\circ} \mathrm{C}$ to avoid thermal degradation of fillers and uniform melting of matrix material. Uniform flow of metal was achieved by maintaining the $2-3$ bar of injection pressure manually. Specifications of the Plastic Injection molding machine is listed in Table 2.

Table 2. Plastic Injection Molding Machine Specifications

\begin{tabular}{|c|l|l|}
\hline S. No & \multicolumn{1}{|c|}{ Description } & \multicolumn{1}{c|}{ Values } \\
\hline 1 & Diameter of Plunger & $45 \mathrm{~mm}$ \\
\hline 2 & Plasticizing Capacity & $20-22 \mathrm{~kg}$ per hour \\
\hline 3 & Screw L/D ratio & $22: 1$ \\
\hline 4 & Maximum operating pressure & $120 \mathrm{bar}$ \\
\hline 5 & Power & $7.5 \mathrm{HP}$ \\
\hline 6 & Heater capacity & $6.5 \mathrm{~kW}$ \\
\hline
\end{tabular}

\section{CELL CULTURE AND MTT ASSAY}

MG63 is a proven and characterized line of cells that has shown reproducible outcome measures. The cell culture was produced by MEM (Minimum Essential Medium) method supplemented with fetal bovine serum. Since this is an effective serum that has the least antibody level and contains more growth factors that allow for flexibility in several applications of cell culture. Cell proliferation and neural cytotoxicity were evaluated by MTT (3-(4, 5-Dimethylthiazol-2-yl)-2, 5-diphenyltetrazolium bromide) assay. After the exposure of composite specimens, the worthwhile cells have efficient mitochondrial dehydrogenate enzymes, which can reduce MTT to form an inexplicable purple Formosan product that is recognizable by electromagnetic spectroscopy. Cells were washed three times with Phosphate 
Buffered Saline ( $\mathrm{pH} 7.3$ ) culture media after cell interactions with composite specimens, and MTT $(0.5 \mathrm{mg} / \mathrm{ml})$ was supplemented to each cell and incubated for $4 \mathrm{~h}$ at $37^{0} \mathrm{C}$.

\section{DIRECT CYTOTOXICITY}

The Ethylene Oxide (EtO) sterilized (i) $30 \mathrm{wt}$ \% of a seashell, and (ii) 30 wt. \% of combinations of fish scale and seashell particulates filled PEHD composite samples were examined through direct in Vitro Cytotoxicity study by means of the MG 63 cell line. The liquid extract of the sterilized specimen is then allowed to chemically react with MG 63 cells using five different concentrations $(10,20,30,40 \& 50 \mu \mathrm{l})$ levels through cellular Cytotoxicity process. The level of cellular Cytotoxicity and cell viability assay of the specimen was analyzed.

\section{EVALUATION OF CYTOTOXICITY}

After Ethylene Oxide sterilization, the (i) $30 \mathrm{wt} . \%$ of the seashell, and (ii) $30 \mathrm{wt} . \%$ of combinations of fish scale and seashell particulates filled PEHD composite were incubated in 1x Phosphate Buffered Saline ( $\mathrm{pH} 7.3$ ) for 24 hat $37{ }^{\circ} \mathrm{C}$. Fresh cell culture medium was introduced in the place of culture medium from the MG-63 cells. The liquid extract of, (i) 30 wt. $\%$ of the seashell, and (ii) $30 \mathrm{wt} \% \%$ of combinations of fish scale and seashell particulates filled polymer composite samples at five different combinations of triplicates were supplemented to the cells. The MTT assay $(1 \mathrm{mg} / \mathrm{ml})$ was applied to all wells after incubation at $37 \pm 1^{\circ} \mathrm{C}$ for 18 hours and incubated for 4 hours. After incubation, organic sulphur was applied to the wells with a small amount of Dimethyl sulfoxide $\left(\mathrm{C}_{2} \mathrm{H}_{6} \mathrm{OS}\right)$, and cytotoxicity findings were revealed using a photometer at $570 \mathrm{~nm}$. Using the following equations, as shown below, cell viability and Cytotoxicity were determined.

$$
\begin{aligned}
& \text { Cytotoxicity }=100 \times[(\text { Control }- \text { Treated }) / \text { Control }] \\
& \text { Cell viability }=100 \times(\text { Treated } / \text { Control })
\end{aligned}
$$

Table 3. Comparison of Reactivity levels (Balaji Ayyanar, \& Marimuthu, 2019).

\begin{tabular}{|c|c|c|}
\hline S.No & Grade Percentage & Levels of Reactivity \\
\hline 1 & 0 & None \\
\hline 2 & $1-20$ & Slight \\
\hline 3 & $21-50$ & Mild \\
\hline 4 & $51-70$ & Moderate \\
\hline 5 & $>71$ & Severe \\
\hline
\end{tabular}


The percentage grade of Cytotoxicity was assessed by the process of direct Cytotoxicity and the grades were compared with standard reference data as shown in Table. 3. Seashell and fish scale filled composite sample specimens are shown in Figure 3.

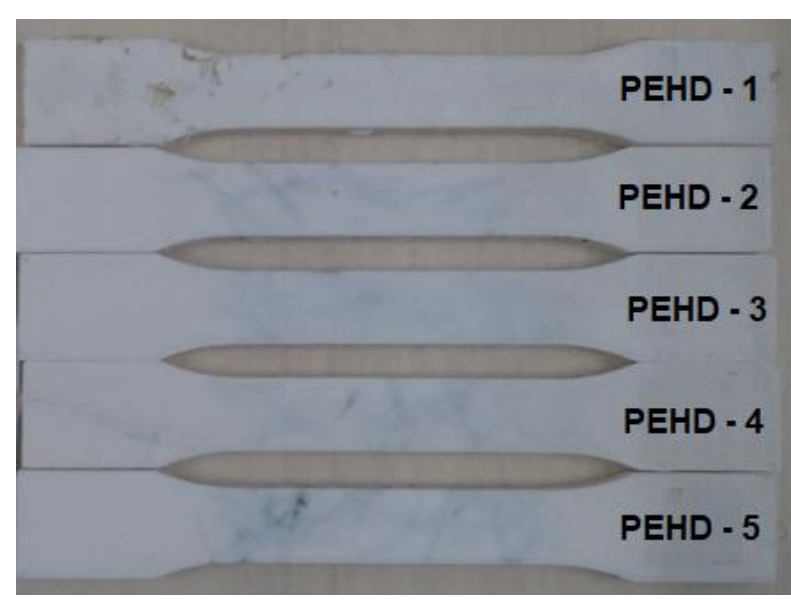

Figure 3 Sample Specimens

\section{RESULTS AND DISCUSSION}

\section{FESEM surface morphology of seashell particulates filled PEHD}

The morphology of seashell particulates was examined using FESEM. A FESEM photomicrograph of the seashell powder particulates reveals that the powder was elongated fibrils in one direction, and it has more irregular shapes and the structured surface is shown in Figure 4 (a-b). Similarly, the powder particulates have rougher and larger surface areas.
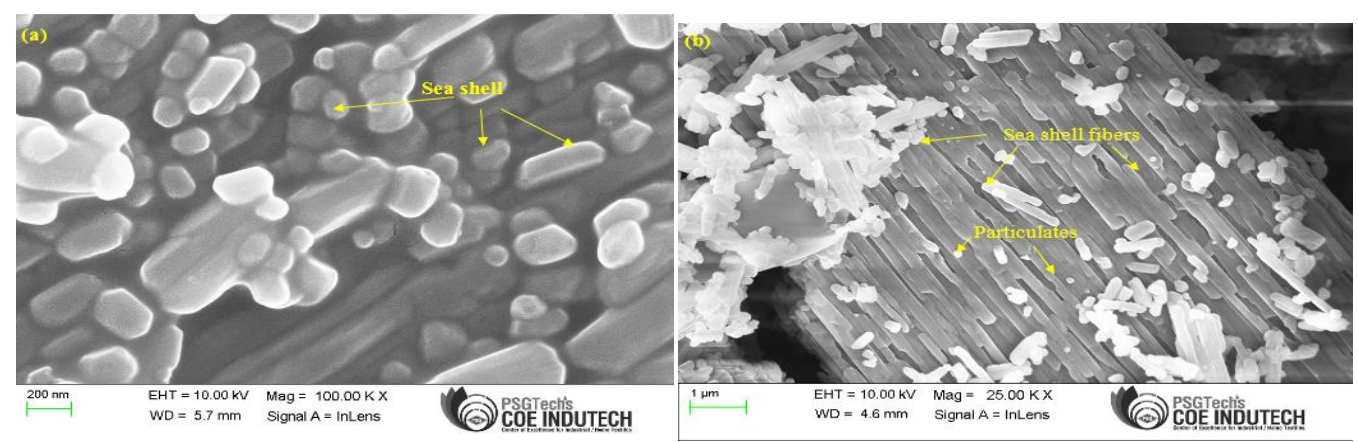

Figure 4 (a-b). FESEM surface morphology seashell particulates

\section{FESEM surface morphology of fish scale and seashell particulates filled PEHD}

FESEM photomicrograph of fish scale and seashell particulates reinforced polymer matrix samples were examined. The FESEM photomicrograph of a fish scale and seashell particulates blended composite is presented in Figure 5 (a-b) and it depicts the exposed particulates. 


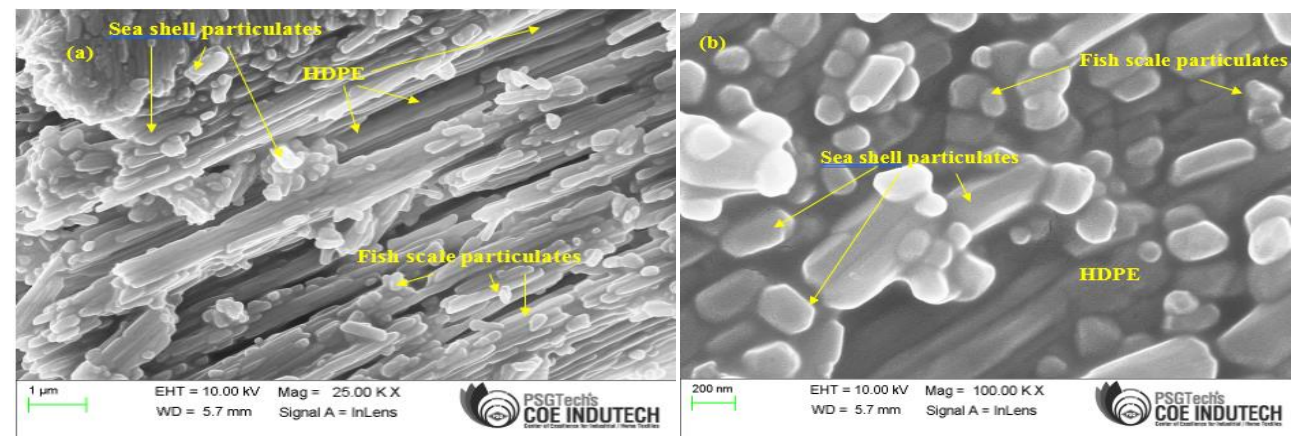

Figure 5 (a-b). FESEM image of seashell and fish scale particulates reinforced polymer composite

The micrograph shows the homogeneously dispersed fish scale and seashell particulates filled with PEHD. The background white with grey color represents the matrix material (PEHD) and a white colored shining silver particle represents the fish scale particulates and shorter length fiber shapes are indicates the seashell particulates. Fish scale and seashell particulates dispersed in the composite was revealed in this FESEM image. Interfacial bonding between the matrix and reinforcements are clearly demonstrated in this image.

\section{Cytotoxicity of fish scale particulates reinforced polymer composite}

Fish scale reinforced polymer composite specimens are reacted with 10, 20, 30, 40 \& $50 \mu \mathrm{l}$ concentrations of extract by direct Cytotoxicity method and results are listed in Table 4. Highest percentage of Cytotoxicity as 5.8 was obtained, when the $50 \mu$ l of liquid extract chemically react with composite specimens (Balaji Ayyanar\& Marimuthu, 2019).

Table 4. Cytotoxicity of $30 \mathrm{wt}$. \% fish scale particulate filled composite material

\begin{tabular}{|c|c|c|c|c|}
\hline \multicolumn{2}{|c|}{ Sample Particulars } & Cytotoxicity \\
Description & $\begin{array}{c}\text { The volume of the } \\
\text { extract }(\mu \mathrm{l})\end{array}$ & $\begin{array}{c}\text { Cell } \\
\text { viability }(\%)\end{array}$ & $\begin{array}{c}\text { Cytotoxicity } \\
\text { reactivity }\end{array}$ \\
\hline \multirow{3}{*}{$\begin{array}{l}\text { 30 } \\
\text { particulate Fish scale } \\
\text { PEHD composite filled }\end{array}$} & 20 & 0 & $>99$ & None \\
\cline { 2 - 5 } & 30 & 0 & $>99$ & None \\
\cline { 2 - 5 } & 40 & 1.7 & 99.4 & Slight \\
\hline
\end{tabular}

\section{Evaluation of Cytotoxicity of seashell particulate filled PEHD composite}

Seashell reinforced polymer composite specimens are reacted with 10, 20, 30, $40 \& 50$ $\mu \mathrm{l}$ concentrations of extract by direct Cytotoxicity method (Oktay Yigit et al., 2020). Highest 
percentage of Cytotoxicity as 40 was obtained, when the $50 \mu 1$ of liquid extract chemically react with composite specimens.

Fresh culture extract of $10,20,30,40$, and $50 \mu \mathrm{l}$ concentrations allowed to chemically reacting with polymer matrix composite specimens. In Table 4, Cytotoxicity level and cell viability of crushed seashell particles filled composite were compared. $40 \& 50 \mu 1$ of extract volume exhibits close results with $1 \%$ variation. Correlation between the volume of extract $(\mu \mathrm{l})$ and percentage of cell viability is shown in Figure 7 by direct Cytotoxicity test. The maximum Cytotoxicity level of $37-40 \%$ is achieved among 30-50 volume of the extract and the corresponding reactivity level was within the acceptable limit as Mild. Survivability of cell is same as well as high for $10 \& 20$ of fresh culture extract as shown in Figure 6

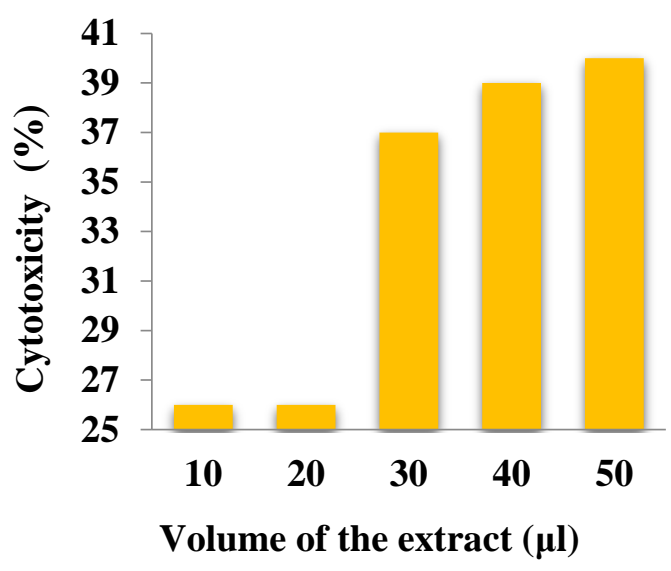

Figure 6. Cytotoxicity (\%) 30 wt. \% of seashell particulate filled PEHD composite material

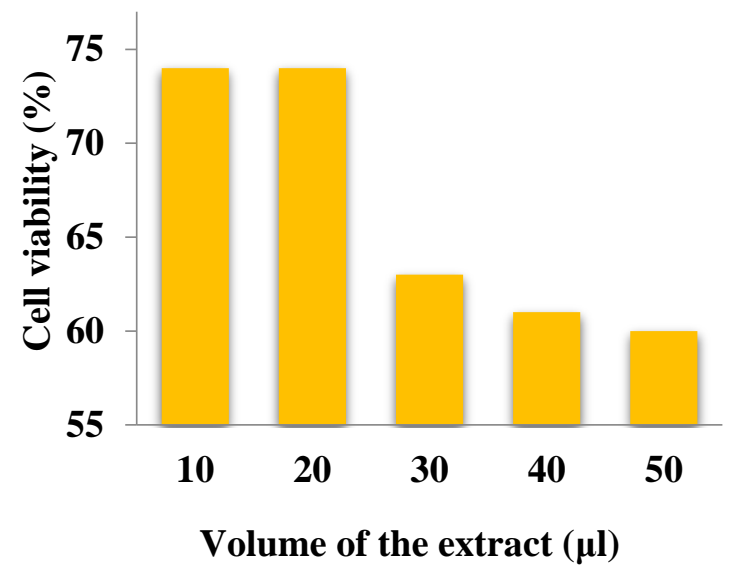

Figure 7. Cell viability (\%) 30 wt. \% seashell particulate filled PEHD composite material

Illuminance and irradiation are measured by Photometer instrument with $570 \mathrm{~nm}$ wavelength light source. Figure 7 depicts the cell morphology of MG63 cells after interacting (a-e) with liquid extracts $(10,20,30,40,50 \mu 1)$. Number of cells, orientation of cell and size of cell are the factors to calculate the cell viability using $570 \mathrm{~nm}$ photometer. The presents of dark purple colored points in the image are indicates the viability of cell. Name of the figure Control represents the fresh culture extract and other consecutive image represents the 10,20, $30,40 \& 50 \mu \mathrm{l}$ of liquid extract mixed with fresh culture medium. Photometer results of fresh culture (control) compared with other liquid extract.

$10,20,30,40 \& 50 \mu \mathrm{l}$ of liquid extract was reacted with composite specimen separately and their photographs were examined by photometer to reveal the cell viability. Living and non-living cells present in the culture was identified through hairlines and circular bubbles. 10 $\mu \mathrm{l}$ liquid extract mixture produces $74 \%$ of cell viability, percentage of Cytotoxicity was 26 
with the reactivity level of Mild and others also in the same range. Low toxicity and high viability of cell was observed in the seashell particulates reinforced composite is at $10 \mu \mathrm{l}$. As compared with fish scale particulates, seashell particulate releases the considerable amount of toxicity.

\section{Evaluation of Cytotoxicity fish scale and seashell particulates filled PEHD composite}

The grade (\%) of Cytotoxicity and cell viability of the 30 wt. \% fish scale and sea shell particulates filled PEHD composite specimen was calculated for different volumes of the extract $(10,20,30,40$, and $50 \mu \mathrm{l})$ by direct Cytotoxicity test. The obtained results are compared with standard reference data of Cytotoxicity reactivity in Table. 4 and the result are tabulated.

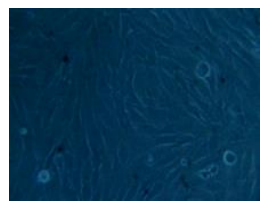

control

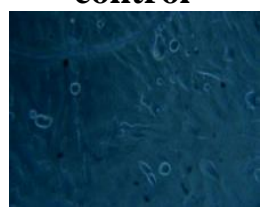

(c)

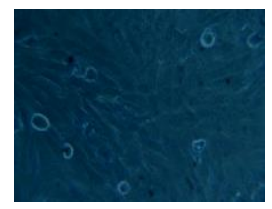

(a)

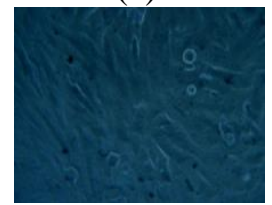

(d)

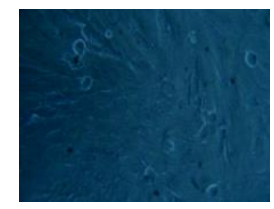

(b)

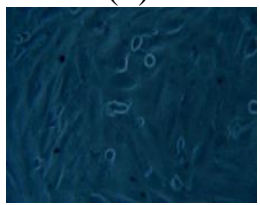

(e)

Figure 8. (a-e) Cell morphology of MG63 cells after interacting (a-e) with liquid extracts (10,

$$
20,30,40,50 \mu 1)
$$

Figure 9 depicts the level of Cytotoxicity (\%) of 30 wt. \% fish scale and sea shell particulates filled PEHD composite specimens with five different volumes of the extract (10, 20, 30, 40, and $50 \mu \mathrm{l}$ ) allowed are interacted with fresh culture medium by direct Cytotoxicity test. The level of Cytotoxicity (\%) obtained was a maximum of 50 for $50 \mu$ liquid extract of the specimen interacted with fresh medium. The levels of Cytotoxicity $50 \%$ were compared in Table1.

The level of Cytotoxicity of $50 \%$ is between the grades of $3(21-50 \%)$. The reactivity level was under a slight level which is within an acceptable range. The Figure 10 depicts the level of cell viability (\%) of the composite specimen having five different volumes of the extract $(10,20,30,40$, and $50 \mu \mathrm{l})$ separately interacted with fresh culture medium by direct Cytotoxicity test. 


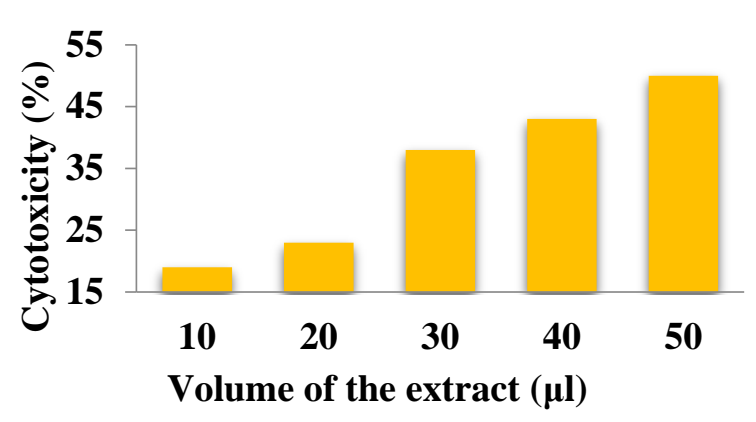

Figure 9. Cytotoxicity (\%) 30 wt. \% of fish scale and seashell particulate filled PEHD composite material.

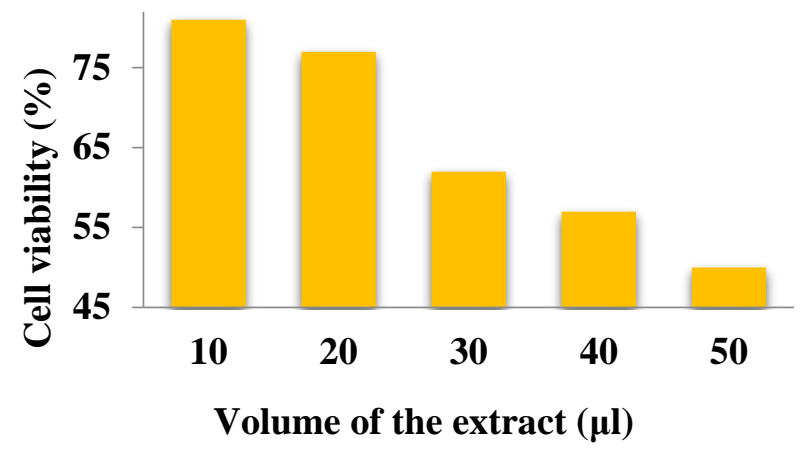

Figure 10. Cell viability (\%) 30 wt. \% fish scale and seashell particulate filled PEHD composite material

$10,20,30,40 \& 50 \mu \mathrm{l}$ of liquid extract was mixed with fresh cell culture separately and their photographs were examined by photometer to reveal the cell viability. Living and nonliving cells present in the culture was identified through hairlines and circular bubbles as shown in Figure 11 (a-e). $10 \mu$ liquid extract mixture produces $81 \%$ of cell viability, percentage of Cytotoxicity was 19 with the reactivity level of Slight and others lies in the range of Mild.

The maximum level of mixture $(50 \mu \mathrm{l})$ produces $50 \%$ of cell viability and mild Cytotoxicity.

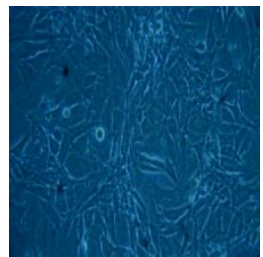

control

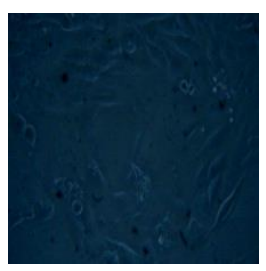

(c)

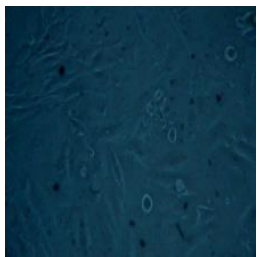

(a)

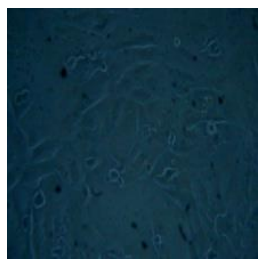

(d)

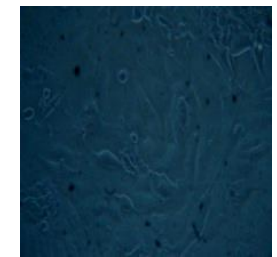

(b)

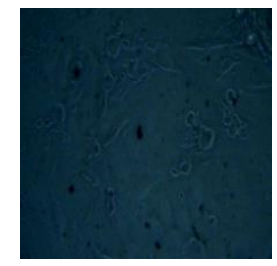

(e)

Figure 11. (a-e) Cell morphology of MG63 cells after interacting (a-e) with liquid extracts (10,

$$
20,30,40,50 \mu 1)
$$

From the results, it was observed that the Cytotoxicity cell varies inversely to the viability of cell. The percentage of difference between low to higher level of mixture was $64 \%$ cytotoxicity and $38 \%$ of cell viability. 


\section{Comparison of cytotoxicity $(\%)$}

The grade (\%) of Cytotoxicity of the seashell, the combination of fish scale and seashell particulates filled polymer matrix composite samples was examined through Cytotoxicity and test results are plotted in Figure 12 to depict the comparison of Cytotoxicity (\%).As compared with other samples $50 \mu \mathrm{l}$ of fresh culture interacted with composite specimen exhibits higher level of cytotoxicity. Fish scale reinforced composite specimen reacted with 10 and $20 \mu \mathrm{l}$ of fresh culture extract produces zero percentage of cytotoxicity. Overall observation from the results is in increasing order for all the three type of composite specimens (Fereydoun Pourdanesh et al., 2014).

Fish scale reinforced composite samples exhibits low cytotoxicity than others. This result reveals that the interaction of fish scale particle reinforced composite with culture extract is not as much of others. The mean cytotoxicity between fish scale with seashell is $95.5 \%$, fish scale with fish scale + seashell is $95.34 \%$ and seashell with fish scale + seashell is $2 \%$. Mean value of cytotoxicity between the mixture of seashell and fish scale, seashell based composite exhibits closure results.

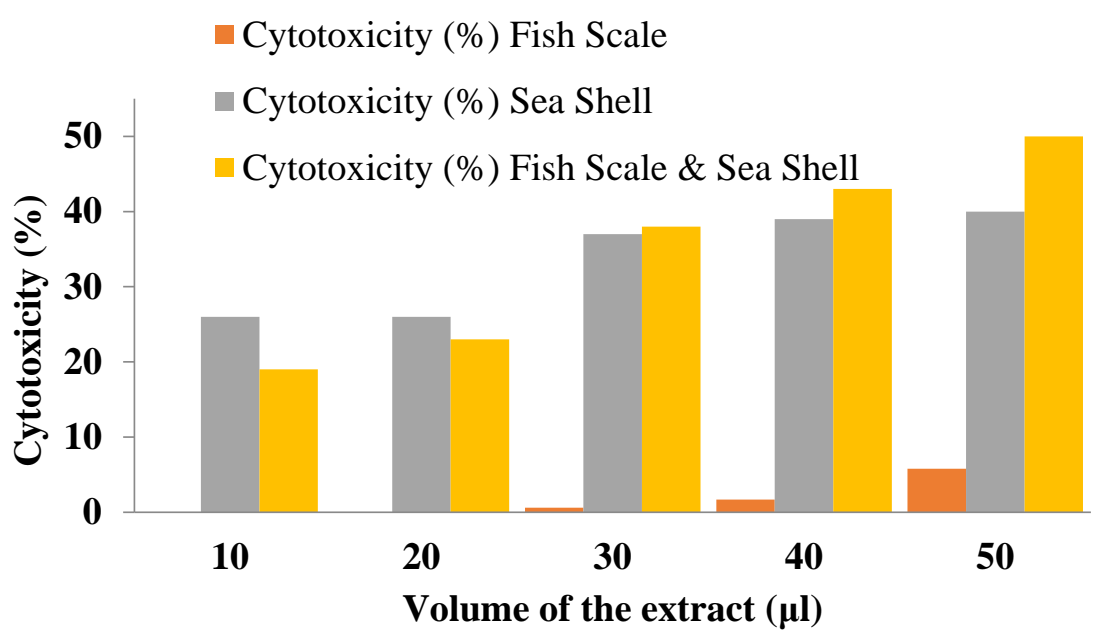

Figure 12. Comparison of Cytotoxicity (\%)

Interaction of $10 \mu \mathrm{l}$ and $20 \mu \mathrm{l}$ culture extract with fish scale and seashell filled PEHD composite extract exhibited 19 and $23 \%$ of cytotoxicity level. Interaction of $30 \mu \mathrm{l}$ fish scale and seashell filled PEHD composite exhibited 38\% of cytotoxicity with Slight level. The culture medium interacted with $40 \mu \mathrm{l}$ fish scale and seashell filled PEHD composite exhibited $43 \%$ slight Cytotoxicity. Interaction of $50 \mu \mathrm{l}$ fish scale and seashell filled PEHD composite exhibited $50 \%$ of cytotoxicity with a level of slight. 
Among the above three combinations, the fish scale filled PEHD composite exhibited the least level of toxicity of maximum $5.8 \%$ compared with the $40 \%$ seashell filled PEHD composite and $50 \%$ fish scale and seashell filled PEHD. Since fish scale filled PEHD composite exhibited the Cytotoxicity reactivity is within the slight level. Since these combinations have preferred and further research has been carried out.

\section{Comparison of cell viability $(\%)$}

Seashell, fish scale and the mixture of seashell and fish scale reinforced composite specimens could chemically react with five different volume starting from 10 to $50 \mu$ of fresh culture extract was tested through direct cytotoxicity test and the results are plotted in Figure 13. to depicts the comparison of cell viability (\%).

$10 \mu \mathrm{l}$ and $20 \mu \mathrm{l}$ of culture mixture chemically react with fish scale filled PEHD composite excerpt produces $99 \%$ cell viability. $30 \mu \mathrm{l}$ of culture mixture chemically react with fish scale filled PEHD composite exhibited $99.4 \%$ cell viability. The culture medium interacted with $40 \mu \mathrm{l}$ fish scale filled PEHD composite exhibited 98.3\%. The culture medium interacted with $50 \mu \mathrm{l}$ fish scale filled PEHD composite exhibited $98.3 \%$ cell viability (Morteza Asadollahzadeh et al., 2019).

The culture medium interacted with $10 \mu \mathrm{l}$ and $20 \mu \mathrm{l}$ seashell filled PEHD composite extract exhibited $74 \%$ cell viability. The culture medium interacted with $30 \mu 1$ seashell filled PEHD composite exhibited $63 \%$ cell viability. The culture medium interacted with $40 \mu \mathrm{l}$ seashell filled PEHD composite exhibited $61 \%$ cell viability. The culture medium interacted with $50 \mu \mathrm{l}$ seashell filled PEHD composite exhibited $60 \%$ cell viability.

$10 \mu \mathrm{l}$ and $20 \mu \mathrm{l}$ of extract added with fresh culture allowed to chemically react with fish scale and seashell filled PEHD composite extract exhibited 81 and $77 \%$ cell viability. The culture medium interacted with $30 \mu \mathrm{l}$ fish scale and seashell filled PEHD composite exhibited $62 \%$ cell viability. The culture medium interacted with $40 \mu \mathrm{l}$ fish scale and seashell filled PEHD composite exhibited $57 \%$ cell viability. The culture medium interacted with $50 \mu \mathrm{l}$ fish scale and seashell filled PEHD composite exhibited $50 \%$ cell viability. 


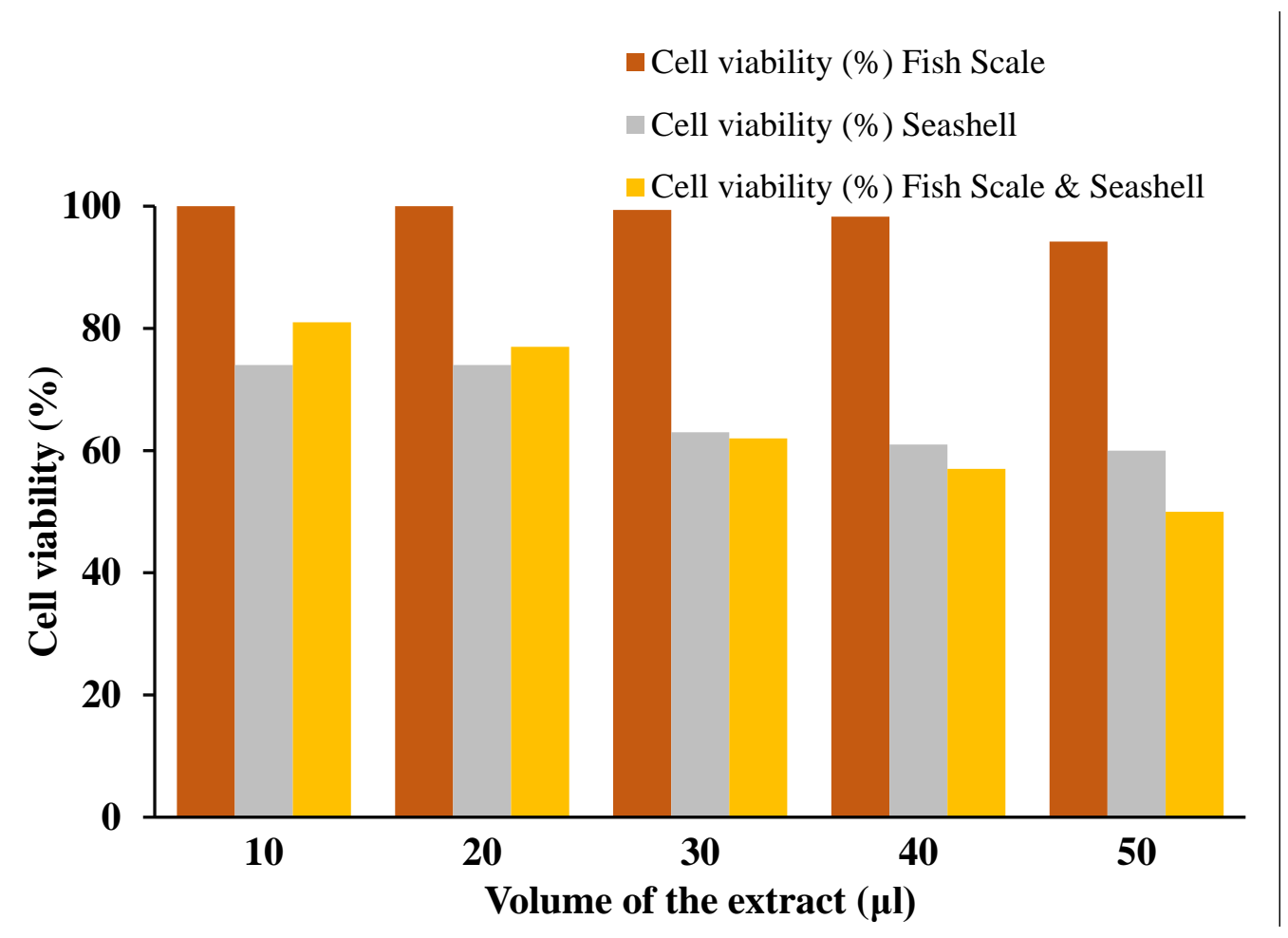

Figure 13. Comparison of Cell viability (\%)

From the above three combinations, fish scale reinforced polymer matrix composite samples were exhibits $99 \%$ of cell viability. Seashell reinforced composite samples exhibits 25 $\%$ of cell viability lower than the seashell reinforced composite. The mixture of seashell and fish scale reinforced composite samples exhibits $18 \%$ lower than fish scale and $7 \%$ higher than the mixture of seashell and fish scale filled composite specimens. The PEHD composite specimen filled with fish scale exhibited the highest cell viability with low toxicity.

\section{CONCLUSION}

As per the ISO 10993:5 standard, the direct in vitro Cytotoxicity experimentation was carried out with $24 \mathrm{~h}$ contact period. The direct in vitro experimentation result reveals that the natural fiber reinforced PEHD composite specimens Cytotoxicity of the test sample exhibits none - slight Cytotoxicity level with MG63 cells. Among the above three combinations the 30 wt. \% fish scale filled PEHD composite exhibited the least level of toxicity of a maximum of $5.8 \%$ compared with the 30 wt. \% sea shell filled PEHD composite exhibited $40 \%$ of toxicity, and fish scale and seashell filled PEHD composite exhibited $50 \%$ of toxicity. Zero toxicity and $99 \%$ of cell viability were observed in the fish scale filled PEHD composite through cytotoxicity test. Next to the fish scale, the mixture of seashell and fish scale reinforced composite exhibits $81 \%$ of cell viability with 19 to $50 \%$ of toxicity level. From this 
exhaustive research, the fish scale particulates reinforced polymer matrix composite exhibits the highest cell viability with zero toxicity.

\section{ACKNOWLEDGMENT}

The author would like to thank the management board and staff of the Department of Mechanical Engineering, Bannari Amman Institute of Technology for the supports and facilities during the research.

\section{REFERENCES}

Dhanaraj, K., \&Suresh, G. 2018. Conversion of waste seashell (Anadara Granosa) into valuable nanohydroxyapatite (nHAp) for biomedical applications. Vacuum, 152: 222230.

Morteza Asadollahzadeh, Sayed Mahmood Rabiee, \& Hamed Salimi-Kenari. 2019. In vitro apatite formation of calcium phosphate composite synthesized from fish bone. International Journal of Applied Ceramic Technology, 16: 1969-1978.

Hassan Nosratiac., Rasoul Sarraf-Mamoory., Maria Canillas Perez., Dang Quang Svend Le, Reza Zolfaghari Emameh., \& Cody Eric Bünger. 2021. Characteristics of hydroxyapatite-reduced graphene oxide composite powders synthesized via hydrothermal method in the absence and presence of diethylene glycol. Open Ceramics, 5: 1-10.

Dhanaraj, K., \& Suresh, G. 2018. Conversion of waste sea shell (Anadara granosa) into valuable nanohydroxyapatite (nHAp) for biomedical applications. Vacuum, 152: 222230.

Clavijo- Mejíaab, G.A., Hermann-MuñozaJ, J.A., Rincón-Lópeza, A., Ageorgesb, A., \& Muñoz-Saldaña, A. 2020. Bovine-derived hydroxyapatite coatings deposited by highvelocity oxygen-fuel and atmospheric plasma spray processes: A comparative study. Surface and Coatings Technology, 381: 2411-2502.

Kristine Salma-Ancane., \& Liga Stipniece Zilgma Irbe. 2016. Effect of biogenic and synthetic starting materials on the structure of hydroxyapatite bioceramics. Ceramics International, 8: 9504-9510.

Fatemeh Heidari., Fahimeh Sadat Tabatabaei., Mehdi Razavi., Reza Bazargan Lari., Mina Tavangar., Georgios E. Romanos., Daryoosh Vashaee., \& Lobat Tayebi. 2020. 
3D construct of hydroxyapatite/zinc oxide/palladium nanocomposite scaffold for bone tissue engineering. Journal of Materials Science: Materials in Medicine, 31: 1-14

Francesca Cestari., Francesca Agostinacchio., Anna Galotta., Giovanni Chemello., Antonella Motta., \& Vincenzo M. Sglavo. 2021. Nano-Hydroxyapatite Derived from Biogenic and Bioinspired Calcium Carbonates: Synthesis and In Vitro Bioactivity. Nanomaterials, 264(11): 1-14

Muhamamd Auchar Zardari. 2020. Structural behaviour of large size compressed earth blocks stabilized with jute fiber. Journal of Engineering Research, 8(2): 60-72.

Payam Majedi., Suat Akbulut., \& Zeynep Nese Kurt. 2019. Some geotechnical properties and damping ratio of clay nanocomposites. Journal of Engineering Research, 7(1): 1-16.

Fereydoun Pourdanesh., Ali Jebali., Seyedhossein Hekmatimoghaddam., \& Azra Allaveisie. 2014. In vitro and in vivo evaluation of a new nanocomposite, containing Polyethylene high-density, tricalcium phosphate, hydroxyapatite, and magnesium oxide nanoparticles. Materials Science and Engineering C, 40: 382-388.

Balaji Ayyanar, C., \& Marimuthu, K.2019. Investigation on the morphology, thermal properties, and in vitro Cytotoxicity of the fish scale particulates filled high-density polyethylene composite. Polymers and Polymer Composites, DOI: 10.1177/0967391119872877.: 1-12.

Baolin Huang., Yuan Yuan., Sai Ding., Jianbo Li., Jie Ren., Bo Feng., Tong Li., Yuantong Gu., \& Changsheng Liu. 2015. Nanostructured hydroxyapatite surfaces-mediated adsorption alters recognition of BMP receptor IA and bioactivity of bone morphogenetic protein-2. Acta Biomater, 27: 275-285.

Oktay Yigit., Burak Dikici., Taha Cagri Senocak., \& Niyazi Ozdemir. 2020. One-step synthesis of nano-hydroxyapatite/graphene nanosheet hybrid coatings on Ti6Al4V alloys by hydrothermal method and their in-vitro corrosion responses. Surface and Coatings Technology, 394: 1-36

Anandha Moorthy Appusamy., Prakash Eswaran., Madheswaran Subramani., \& Santhanakumar Sadaiappan. 2018. Experimental studies on Mechanical properties and Characterization of Parthenium Short Fibre Reinforced Polymer Matrix Composites. International Journal of Engineering and Advanced Technology, 8 (2S): 94-97. 